\title{
Persistence of Essential Fatty Acid Deficiency in Cystic Fibrosis Despite Nutritional Therapy
}

\author{
LUIS ALDÁMIZ-ECHEVARRÍA, JOSÉ ANGEL PRIETO, FERNANDO ANDRADE, JAVIER ELORZ, AMAIA SOJO, SERGIO LAGE, \\ PABLO SANJURJO, CARLOS VÁZQUEZ, AND JUAN RODRÍGUEZ-SORIANO
}

Department of Pediatrics, Cruces Hospital and Basque University School of Medicine, Bilbao, 48903 Basque Country, Spain

\begin{abstract}
To study the evolution of plasma fatty acid composition of patients with cystic fibrosis $(\mathrm{CF})$ in relation to nutritional status, pancreatic function, and development of CF-related liver disease (CFRLD) and diabetes mellitus, $24 \mathrm{CF}$ pediatric patients with stable pulmonary disease were studied before and after an approximate period of $8 \mathrm{y}$. Nutritional status, pulmonary function, pancreatic function, and presence of CFRLD or diabetes mellitus were recorded. Results were compared with data obtained in 83 healthy children. Patients with CF have significantly lower linoleic acid (LA), docosahexaenoic acid (DHA), lignoceric acid, and LA $\times$ DHA product and higher oleic acid, mead acid, dihomo- $\gamma$-linoleic acid, and docosapentaenoic acid (DPA). Comparison of samples taken at first and second studies revealed a significant decrease in LA levels and lignoceric acid associated with a significant increase in dihomo- $\gamma$ linoleic acid levels. Patients with CFRLD showed significantly higher mead acid/arachidonic acid ratio and lower total $\omega 6$ polyunsaturated fatty acids content. There was no relation of plasma fatty acids composition with pancreatic function, pulmonary function, or diabetes mellitus. Follow-up of patients with CF shows that essential fatty acids deficiency, particularly in LA and DHA content, persisted unmodified along time despite an adequate nutritional therapy. Future studies after supplementation with $\omega 3$ polyunsaturated fatty acids should be undertaken. (Pediatr Res 66: 585-589, 2009)
\end{abstract}

$\mathrm{C}$ ystic fibrosis (CF) is the most common autosomal recessive disease in the white population. CF is caused by mutations in the gene encoding for the $\mathrm{CF}$ transmembrane conductance regulator (CFTR). More than 1300 mutations have been identified, but the most frequent mutation is a deletion of phenylalanine in position 508 ([Delta]F508), which results in defective synthesis and folding of the mutant protein with failure to reach the apical membrane of many epithelial cell types. The search for a genotype-phenotype correlation has not been very successful, with modifier genes and environmental factors playing a part in determining severity of the disease (1).

The prognosis of CF has improved steadily over the past five decades, mainly because of aggressive treatment before the onset of irreversible pulmonary changes. Adequate nutritional therapy has been a basic element for the improvement in the quality of life of the patients (2). However, increased

Received April 30, 2009; accepted June 19, 2009

Correspondence: Luis Aldámiz-Echevarría, M.D., Department of Pediatrics, Hospital de Cruces, Plaza de Cruces s/n, Baracaldo, 48903 Vizcaya, Spain; e-mail: luisjose. aldamiz-echevarazuara@osakidetza.net

Supported by Basque Government and Spanish Ministry of Health (Grants 2005111071 and FIS PI05/1236, respectively), as well as Red SAMID (FIS). survival rates have revealed the development of varied metabolic alterations, and different reports have pointed out that essential fatty acid (EFA) deficiency may play an important role in symptoms and disease progression (3-5). The pattern found is a decrease in plasma content of both linoleic (LA) and docosahexaenoic acids (DHA), without gross alteration in the content of the precursor of the $\omega 3$ series, $\alpha$-linolenic acid $(6-8)$. This profile is different from that usually present in typical nutritional EFA deficiency (9). Fatty acid composition may be influenced by genetic factors as shown in murine models $(10,11)$ or in humans $(12)$. The role played by pancreatic insufficiency may also be especially relevant because fat malabsorption persists in many patients despite pancreatic enzyme replacement (13).

We report herein plasma fatty acid composition in 24 patients with CF followed up as a cohort for a period of $\sim 8 \mathrm{y}$ to establish its relationship with nutritional status, pancreatic function, and development of CF-related liver disease (CFRLD) and diabetes mellitus.

\section{PATIENTS AND METHODS}

We have studied 24 patients with CF (15 men, 9 women) meeting the consensus-statement requirement for the diagnosis of this disease (14) and regularly followed up in our center. Twenty-two of the 24 patients presented the mutation [Delta]F508 in at least one of the alleles and 9 were homozygous for the mutation. Patients were studied twice: before and after an approximate period of $8 \mathrm{y}$. Age ranged from $7.8 \pm 3.9 \mathrm{y}$ at the first study to $14.0 \pm 3.6 \mathrm{y}$ at the second study.

Patients ingested a diet providing a calorie intake of about $120 \%$ of RDA with $35-40 \%$ of calories coming from fat. No supplementation with $\omega 3$ polyunsaturated fatty acids (PUFA) was given. All patients who were pancreatic insufficient received supplements of fat soluble vitamins containing cholecalciferol (1,000 IU), $\alpha$-tocopherol acetate $(100 \mathrm{mg})$, phytomenadion $(1 \mathrm{mg})$, retinol acetate (10,000 IU), and pancreatic enzyme replacement therapy (15).

Control group was formed by 83 healthy children (age: $6.2 \pm 3.6$ y) who were undergoing minimal surgical procedures. None of them had history of chronic or recent illness, and they were not taking any medication.

The study was reviewed and approved by the ethics committee of the hospital. Informed consent from the children and/or parents was obtained.

Clinical and anthropometric studies. Genotypes were determined with the INNO-LiPA CFTR19 and INNO-LiPA CFTR17+Tn Update kit (Innogenetics N.V.) or sequencing of the CFTR genome. Nutritional status was assessed by BMI [weight (gram)/height ${ }^{2}$ (square meter)]. Anthropometric values were expressed as $z$ scores using Spanish reference data (16). Respiratory involvement was assessed by lung function testing. Forced expiratory volume in $1 \mathrm{~s}$

\footnotetext{
Abbreviations: AA, arachidonic acid; CF, cystic fibrosis; CFRLD, cystic fibrosis related liver disease; CFTR, cystic fibrosis transmembrane conductance regulator; DHA, docosahexaenoic acid; DPA, docosapentaenoic acid; EFA, essential fatty acid; LA, linoleic acid; MUFA, monounsaturated fatty acids; PUFA, polyunsaturated fatty acids; SFA, saturated fatty acids
} 
was expressed as percentage of the predicted value for age, sex, and height (17). Exocrine pancreatic sufficiency were defined as a fecal elastase-1 concentration $>200 \mathrm{IU} / \mathrm{g}$ or a fat content in stool samples $<7 \%$ (wt/wt) of the amount of dietary fat (18). The diagnosis of CFRLD was made by ultrasonography of the liver. According to Williams et al. (19), CFRLD is present when an ultrasound score above 6 is associated with a splenomegaly. None of our patients with CFRLD had ascites, coagulation disorders, or hypoalbuminemia. CF-related diabetes was defined by requirement for insulin therapy.

Laboratory procedures. Biochemical determinations were carried out in blood drawn in the morning after an overnight fast of $12 \mathrm{~h}$. Blood samples were cooled in an ice-water bath and immediately centrifuged at $1000 \times \mathrm{g}$ for $45 \mathrm{~min}$ at $4^{\circ} \mathrm{C}$. The platelet-poor plasma was aliquoted and stored at $-20^{\circ} \mathrm{C}$ until the assay was performed, usually within a few days.

Fecal elastase-1 was determined with a commercial ELISA kit (SheBo.Tech, Giessen, Germany). Plasma total fatty acids were transmethylated according to Lepage and Roy (20) using tridecanoic acid as the internal standard. The fatty acid methyl esters were separated and quantified on a Hewlett Packard GC 5890 gas chromatograph using a flame-ionization detector on a capillary column SP $2330(30 \mathrm{~m} \times 0.25 \mathrm{~mm}, 0.20 \mathrm{~mm})$ (Supelco, Bellefonte, PA). The oven temperature was $80^{\circ} \mathrm{C}$ at injection, and this was maintained for $1 \mathrm{~min}$, then raised by $50^{\circ} \mathrm{C} / \mathrm{min}$ to $140^{\circ} \mathrm{C}, 5^{\circ} \mathrm{C} / \mathrm{min}$ to $190^{\circ} \mathrm{C}$ and maintained for $5 \mathrm{~min}$, and finally raised by $5^{\circ} \mathrm{C} / \mathrm{min}$ to $215^{\circ} \mathrm{C}$ and isothermally maintained for $15 \mathrm{~min}$. Injector and detector temperatures were $250^{\circ} \mathrm{C}$. Helium was used as the carrier gas under a pressure of 0.5 bars. Identification of fatty acids was performed by comparison with commercial standards (Nu Chek, Elysian, MN).

Quantification of each fatty acid was done by electronic integration. Results for fatty acids are expressed as percent weight. The fatty acids were grouped in saturated fatty acids (SFA) (14:0, 16:0, 17:0, 18:0, 22:0, and 24:0), monounsaturated fatty acids (MUFA) $(14: 1 \omega 5,16: 1 \omega 7,18: 1 \omega 9$, and 24:1 $\omega 9), \omega 6$ PUFA (18:2 $\omega 6,18: 3 \omega 6,20: 3 \omega 6,20: 4 \omega 6,22: 4 \omega 6$, and 22:5 $\omega 6)$, and $\omega 3$ PUFA $(18: 3 \omega 3,20: 5 \omega 3,22: 5 \omega 3$, and 22:6 $\omega 3)$.

The product/precursor ratios were used to calculate the activities of the enzymes involved in fatty acids metabolism: elongase (18:0/16:0), delta 6 desaturase $(18: 3 \omega 6 / 18: 2 \omega 6)$, and delta 5 desaturase $(20: 4 \omega 6 / 20: 3 \omega 6)$. We determined the EFA deficiency by the measurement 20:3 $\omega 9($ mead acid $) / 20: 4 \omega 6$ [arachidonic acid (AA)] ratio and sufficiency of DHA index (22:6 $\omega 3 / 22: 5 \omega 6)$.

Statistical analysis. We performed analysis using SPSS Version 16.0 statistical software. Descriptive statistic is presented as median and interquartile range. Spearman's [rho] test was used to evaluate relationship between continuous variable. Statistically significant differences between groups were analyzed using the Kruskall-Wallis test. The Kendall-Tau test was used to measure correlations between ordinal-level variables and the strength of their relationships. All $p$ values are two tailed, and the level of significance was $p<0.05$.

\section{RESULTS}

Anthropometric and clinical findings. Table 1 summarizes anthropometric and clinical findings in patients with $\mathrm{CF}$ at first and second studies. No significant changes took place in SDS values for height, weight, and BMI. All, except one, evidenced signs of exocrine pancreatic insufficiency at both studies. At

Table 1. Anthropometric and clinical studies (mean $\pm S D)$

\begin{tabular}{lccc}
\hline & $\begin{array}{c}\text { First study } \\
(n=24)\end{array}$ & $\begin{array}{c}\text { Second study } \\
(n=24)\end{array}$ & $p$ \\
\hline Age $(\mathrm{y})$ & $7.8 \pm 3.9$ & $14.0 \pm 3.6$ & $<0.001$ \\
Height $(\mathrm{cm})$ & $121.1 \pm 23.4$ & $151.3 . \pm 14.9$ & $<0.001$ \\
$\quad$ SDS & $-0.73 \pm 0.74$ & $-0.98 \pm 0.82$ & $\mathrm{NS}$ \\
Weight $(\mathrm{kg})$ & $26.5 \pm 11.9$ & $45.6 \pm 10.6$ & $<0.001$ \\
$\quad$ SDS & $-0.61 \pm 0.50$ & $-0.73 \pm 0.58$ & $\mathrm{NS}$ \\
BMI $\left(\mathrm{kg} / \mathrm{m}^{2}\right)$ & $17.1 \pm 2.1$ & $19.4 \pm 3.1$ & $<0.001$ \\
$\quad$ SDS & $-0.33 \pm 0.75$ & $-0.39 \pm 0.69$ & $\mathrm{NS}$ \\
FEV1 $(\%$ of predicted) & $97.0(63.7-129.0)$ & $105.5(95.6-115.9)$ & $\mathrm{NS}$ \\
Exocrine pancreatic & $23 / 24$ & $23 / 24$ & $\mathrm{NS}$ \\
$\quad$ insufficiency $(n)$ & & & \\
CF-related liver & $5 / 24$ & $9 / 24$ & $\mathrm{NS}$ \\
$\quad$ disease $(n)$ & & & $\mathrm{NS}$ \\
CF-related diabetes & $4 / 24$ & & \\
$\quad$ mellitus $(n)$ & & & \\
\hline
\end{tabular}

Table 2. Metabolic studies (mean, range)

\begin{tabular}{lccc}
\hline & $\begin{array}{c}\text { First study } \\
(n=24)\end{array}$ & $\begin{array}{c}\text { Second study } \\
(n=24)\end{array}$ & $p$ \\
\hline Glucose $(\mathrm{mg} / \mathrm{dL})$ & $82(66-99)$ & $90(76-150)$ & 0.002 \\
Glucose $30(\mathrm{mg} / \mathrm{dL}) *$ & $181.5(111.0-227.0)$ & $132.0(99.0-239.0)$ & $\mathrm{NS}$ \\
Insulin $(\mu \mathrm{U} / \mathrm{mL})$ & $9.7(5.2-19.0)$ & $19.0(12.0-52.0)$ & 0.012 \\
Insulin $30(\mu \mathrm{U} / \mathrm{mL}) *$ & $34.5(16.5-70.5)$ & $28.0(24.0-76.0)$ & $\mathrm{NS}$ \\
Glycosylated $\mathrm{Hb}(\%)$ & $5.6(4.2-7.7)$ & $5.5(4.9-7.8)$ & $\mathrm{NS}$ \\
\hline
\end{tabular}

* Values at $30 \mathrm{~min}$ after an oral glucose load of $1.75 \mathrm{~g} / \mathrm{kg}$ (maximum, $75 \mathrm{~g}$ ).

the second study, nine patients had ultrasonic signs of hepatopathy and six manifested clinical diabetes mellitus. As shown in Table 2, at the second study, plasma values for glucose and insulin had increased significantly.

Plasma fatty acid composition. Plasma fatty acid composition in patients with CF differed significantly from that in healthy controls (Table 3). Overall, in patients with CF, contents of SFA and MUFA were increased, whereas content of PUFA was globally decreased. Among PUFA, mean concentrations of LA, DHA, lignoceric acid, and LA $\times$ DHA product were decreased, whereas those of dihomo- $\gamma$-linoleic acid and docosapentaenoic acid (DPA) were increased. Comparison of samples taken at first and second studies revealed a significant decrease in LA levels and lignoceric acid associated with a significant increase in dihomo- $\gamma$-linoleic acid levels.

Patients who evidenced CFRLD showed significantly higher mead acid/AA ratio at the first study $(0.032 \pm 0.012$ versus $0.022 \pm 0.009, p=0.035)$ and lower total $\omega 6$ PUFA content at the second study $(33.51 \pm 3.79$ versus $37.32 \pm$ $4.49, p=0.041$ ) in comparison with patients without CFRLD. No differences were found between patients with or without diabetes mellitus.

Correlations with anthropometric values. Forced expiratory volume in $1 \mathrm{~s}$ correlated significantly with BMI at both studies $(r=0.47, p=0.031$ and $r=0.53, p=0.009$, respectively) (Table 4$)$.

At the first study, BMI correlated positively with DHA and negatively with $\alpha$-linolenic acid. At the second study, BMI correlated positively with LA and negatively with oleic acid, total MUFA, and mead acid/AA ratio.

Correlations between fatty acid values. At both studies, LA related negatively with oleic acid, total MUFA, mead acid/AA ratio, and $\delta 6$ desaturase. Lignoceric acid related positively with total PUFA and $\omega 6$ PUFA and negatively with oleic acid, total MUFA, and mead/AA ratio, as can be seen in Table 4 .

Comparison between initial and follow-up fatty acid values showed that an increase in $\gamma$-LA predicted a decrease in LA. Initial values for LA correlated positively with follow-up values for AA and $\delta 6$ desaturase.

\section{DISCUSSION}

Our results confirm the known presence of profound alterations in plasma fatty acid profile in patients with $\mathrm{CF}$ with decreased content of both LA and DHA and increased content of DPA $(6-8,12)$. It should be remarked that DHA and DPA levels remained steady over time, whereas LA levels de- 
Table 3. Plasma fatty acid composition (\% wt/wt) (median, quartiles Q1-Q3)

\begin{tabular}{lccc}
\hline & First study $(n=24)$ & Second study $(n=24)$ & Control subjects $(n=83)$ \\
\hline Palmitic acid $(18: 0)$ & $7.6(7.0-8.1)$ & $7.6(7.0-8.3)$ & $7.9(7.5-8.2)$ \\
Lignoceric acid $(24: 0)^{* \dagger}$ & $0.67(0.59-0.72)$ & $0.50(0.44-0.60)$ & $0.78(0.68-0.88)$ \\
Oleic acid $(18: 1 \omega 9 \mathrm{c})^{*}$ & $21.9(19.5-22.7)$ & $22.8(20.8-24.1)$ & $18.9(16.9-21.1)$ \\
Mead acid $(20: 3 \omega 9)^{*}$ & $0.15(0.11-0.26)$ & $0.16(0.14-0.16)$ & $0.12(0.10-0.17)$ \\
LA $(18: 2 \omega 6)^{* \dagger}$ & $27.0(24.3-29.2)$ & $25.2(22.6-27.7)$ & $30.7(27.2-32.8)$ \\
$\gamma$-Linoleic acid $(18: 3 \omega 6)^{*}$ & $0.6(0.5-0.7)$ & $0.6(0.5-0.8)$ & $0.3(0.3-0.4)$ \\
Dihomo- $\gamma$-linoleic acid $(20: 3 \omega 6)^{* \dagger}$ & $1.9(1.6-2.1)$ & $2.1(1.9-2.4)$ & $1.7(1.5-1.8)$ \\
AA $(20: 4 \omega 6)$ & $6.8(6.2-7.7)$ & $7.1(6.4-7.8)$ & $7.2(6.6-7.9)$ \\
DPA $(22: 5 \omega 6)^{*}$ & $0.24(0.20-0.29)$ & $0.25(0.19-0.29)$ & $0.22(0.17-0.26)$ \\
$\alpha$-Linolenic acid $(18: 3 \omega 3)$ & $0.3(0.2-0.5)$ & $0.3(0.2-0.4)$ & $0.3(0.2-0.4)$ \\
EPA $(20: 5 \omega 3)$ & $0.45(0.3-0.6)$ & $0.5(0.3-0.7)$ & $0.5(0.4-0.6)$ \\
DHA $(22: 6 \omega 3)^{*}$ & $1.7(1.2-2.0)$ & $1.9(1.2-2.3)$ & $2.5(2.0-2.8)$ \\
SFA* & $32.7(32.0-33.7)$ & $33.6(30.6-34.6)$ & $31.9(31.1-32.7)$ \\
MUFA* & $26.8(24.3-28.3)$ & $27.4(26.1-29.5)$ & $23.6(21.3-26.0)$ \\
PUFA* & $40.7(38.2-43.1)$ & $39.3(34.9-43.1)$ & $44.0(41.5-46.7)$ \\
$\omega 6$ PUFA & $37.6(35.0-39.6)$ & $36.9(31.3-37.9)$ & $40.6(37.3-43.7)$ \\
$\omega 3$ PUFA* & $3.1(2.6-3.6)$ & $3.2(2.4-4.0)$ & $3.7(2.2-4.2)$ \\
$18: 0 / 16: 0 *$ & $0.35(0.32-0.39)$ & $0.35(0.29-0.38)$ & $0.40(0.36-0.42$ \\
AA $(20: 4 \omega 6) / L A(18: 2 \omega 6)^{*}$ & $0.27(0.19-0-31)$ & $0.28(0.22-0-33)$ & $0.24(0.20-0.28)$ \\
Mead acid $(20: 3 \omega 9) / A A(20: 4 \omega 6)^{*}$ & $0.02(0.02-0.03)$ & $0.02(0.02-0.04)$ & $0.02(0.01-0.02)$ \\
AA $(20: 4 \omega 6) /$ DHA $(22: 6 \omega 3)^{*}$ & $5.0(3.2-5.8)$ & $4.8(3.8-5.6)$ & $3.0(2.5-3.7)$ \\
LA $(18: 2 \omega 6) \times$ DHA $(22: 6 \omega 3)^{*}$ & $46.0(29.9-55.7)$ & $44.5(28.1-69.9)$ & $72.9(59.4-86.9)$ \\
\hline
\end{tabular}

Significance $(p<0.05)$ : * patients $v s$ control subjects; $\dagger$ first study $v s$ second studies.

LA, linoleic acid; AA, arachidonic acid; DPA, docosapentaenoic acid; EPA, eicosapentaenoic acid; DHA, docosahexaenoicoic acid; SFA, saturated fatty acids; MUFA, monounsaturated fatty acids; PUFA, polyunsaturated fatty acids.

Table 4. Significant correlations between parameters

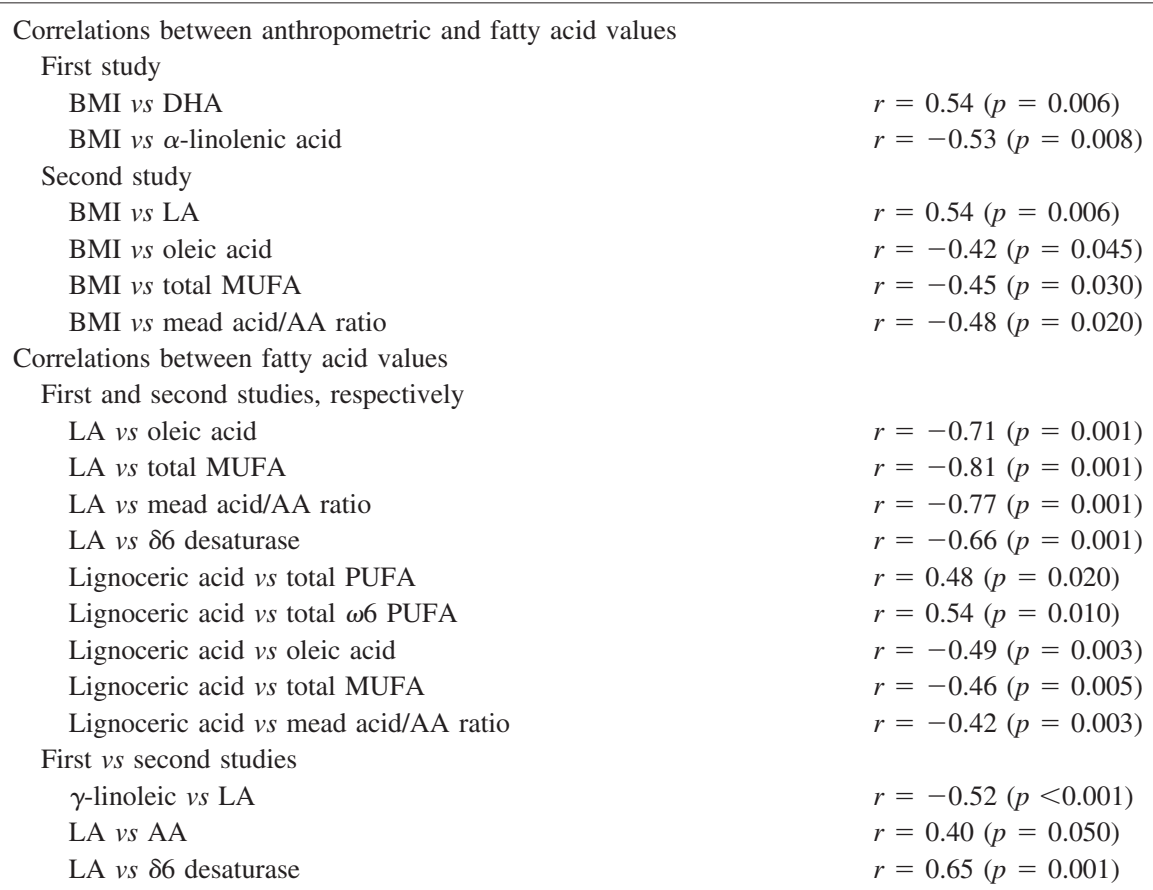

MUFA, monounsaturated fatty acids; LA, linoleic acid; AA, arachidonic acid; EPA, eicosapentaenoic acid; DHA, docosahexaenoicoic acid; sufficiency of DHA index, 22:6 $\omega 3 / 22: 5 \omega 6$.

creased progressively. The LA $\times$ DHA product has been recently proposed as a predictive diagnostic marker to differentiate patients with $\mathrm{CF}$ from non-CF controls: a value $\leq 40$ could be used as a clinical cutoff for CF (21). Our findings support such conclusion because many patients had a LA $\times$ DHA product below 40. Although the patients did not evidence clinical signs of EFA deficiency, the elevation of DPA and mead acid levels suggests that subclinical deficiency was indeed present (22).

It is generally believed that alterations in plasma fatty acid profile in $\mathrm{CF}$ are directly dependent on poor nutrition and fat malabsorption (23). In fact, these factors could play a role in our patients, who presented some degree of exocrine pancreatic insufficiency despite adequate nutritional therapy. 
Significant correlations were found between BMI and several fatty acids, such as LA, $\alpha$-linolenic acid, MUFA, and mead acid/AA ratio. In addition, BMI correlated positively with DHA at the first study, but this correlation was lost posteriorly.

Explanation for the low levels of DHA present throughout the study is less evident if we take into account that plasma levels of this fatty acid are not exclusively dependent on exocrine pancreatic function (24). Competitive metabolism with fatty acids $\omega 6$ or accentuated catabolism could be in cause (25). The behavior of lignoceric acid was especially interesting. Plasma concentration of this fatty acid related better with PUFA than with other SFA. The interpretation of this finding is not apparent but, probably, reflects an increment of its $\beta$-oxidation both at mitochondrial and peroxisomal levels (26). Plasma lignoceric acid could, therefore, be considered as a possible biomarker to follow PUFA supplementation.

Genetic factors may be also implicated in the genesis of EFA deficiency. CFTR is expressed in the apical membranes of various epithelial cells and acts as an important regulator of phospholipid composition (27). It has been shown that in CF cells the incorporation of LA into phospholipids is impaired resulting in increased formation and turnover of AA due to the action of phospholipase $A_{2}$ (28). Both the experimental correction of CFTR mutation and the inhibition of phospholipase $\mathrm{A}_{2}$ permit the liberation of AA from membrane phospholipids suggesting that there is a close association between the genetic defect and plasma fatty acid abnormalities $(29,30)$. Our findings agree with this hypothesis. The significant elevation of the AA/LA ratio indicates that the pathway from LA to AA was enhanced. Furthermore, the association of low levels of LA with normal or high levels of $\alpha$-linolenic acid, oleic acid, mead acid/AA ratio and $\delta 6$ detasurase would suggest that fat malabsorption was not the only causative agent. The different plasma fatty acid profile found in patients with or without CFRLD will support such conclusion.

Over the last decades, many studies have pointed out the fundamental role that $\omega 6$ and $\omega 3$ long chain fatty acids play in the healthy status of human beings (31). The $\omega 6$ long chain fatty acids are precursors of eicosanoids and prostanoids, which are important messengers for endothelial integrity, acid secretion, and inflammatory processes. Liberation of AA from cell membranes, by the action of phospholipase $A_{2}$, is a limitant step in the synthesis of prostanoids (32). Freedman et al. (33) have observed an increased AA/DHA ratio in tissues of cftr $(-/-)$ mice. The authors cannot conclude whether the simultaneous elevation of prostanoids in such tissues represents the cause or the consequence of the inflammatory process observed in CF. Inflammation may also contribute to EFA deficiency through an increased oxidation of fatty acids (34).

The $\omega 3$ long chain fatty acids, and particularly DHA, are structural components of cell membrane phospholipids and are necessary for normal neurologic development $(35,36)$. DHA is also a precursor of several mediators such as docosatrienes, resolvins, and neuroprotein D $(37,38)$. These mediators are involved in the resolution phase of the inflammatory process, which, as mentioned, is enhanced in patients with CF. A decreased bioavailability of DHA may, therefore, have a deleterious effect on tissue functionality and, particularly, on pulmonary and pancreatic cells (24).

As expected, development of CFRLD resulted in aggravation of the EFA deficiency status (12). It should be paid attention to the progressive deterioration of endocrine pancreatic function as revealed by changes in fasting plasma glucose and insulin levels and by the high proportion of patients $(25 \%)$ developing clinical diabetes mellitus over a follow-up period of $8 \mathrm{y}$. In this sense, regular control of blood glycosylated $\mathrm{Hb}$ seemed to be of little value for early detection of this complication. The lack of influence of overt diabetes on plasma fatty acid profile would indicate that the role played by insulin secretion is not relevant.

Nutrition therapy stands as an obligatory tool in the management of patients with CF. There is a consensus that a fat-rich, high-calorie diet should be provided given the persistence of some degree of exocrine pancreatic insufficiency despite oral administration of pancreatic enzymes $(39,40)$. In our patients, nutrition status seemed to be adequate as judged by values of BMI and its close relation with improvement of pulmonary function. However, plasma values of LA and DHA remained persistently diminished along time. Long chain fatty acids of $\omega 3$ series, in the form of fish oil capsules, are easily absorbed by the intestine and become incorporated into plasma and cell membrane phospholipids (41). Daily administration of $150 \mathrm{mg}$ of DHA during $12 \mathrm{wk}$ was followed by a $50 \%$ increase in DHA-containing phosphatidyl choline both in plasma and in red cell membrane phospholipids, associated with a proportional decrease in AA content (42). Therefore, regular administration of $\omega 3 \log$ chain fatty acids could bring an important clinical benefit with lack of adverse effects (43).

In conclusion, follow-up of patients with $\mathrm{CF}$ shows that EFA deficiency, particularly in LA and DHA content, persisted unmodified along time despite an adequate nutritional therapy, which included supplements of fat soluble vitamins and pancreatic enzyme replacement. The persistence of EFA deficiency supports the conclusion that fat malabsorption was not the unique cause of dyslipidemia and that genetic-related endogenous factors may also play an important role on its development. In this sense, it remains to be demonstrated whether oral administration of DHA supplements, as it has been recently recommended, improves $\omega 3$ PUFA deficiency and brings a clear clinical benefit to patients with $\mathrm{CF}$. The potential value of new biomarkers, such as LA $\times$ DHA product or lignoceric acid, to survey such therapeutic intervention should be also investigated.

\section{REFERENCES}

1. Kulczycki LL, Kostuch M, Bellanti JA 2003 A clinical perspective of cystic fibrosis and new genetic findings: relationship of CFTR mutations to genotype-phenotype manifestations. Am J Med Genet 116:262-267

2. Steinkamp G, Wiedemann B 2002 Relationship between nutritional status and lung function in cystic fibrosis: cross sectional and longitudinal analyses from the German CF quality assurance (CFQA) project. Thorax 57:596-601

3. Gibson RA, Teubner JK, Haines K, Cooper DM, Davidson GP 1986 Relationships between pulmonary function and plasma fatty acid levels in cystic fibrosis patients. J Pediatr Gastroenterol Nutr 5:408-415

4. Farrell PM, Mischler EH, Engle MJ, Brown J, Lau SM 1985 Fatty acid abnormalities in cystic fibrosis. Pediatr Res 19:104-109

5. Lloyd-Still JD, Bibus DM, Powers CA, Johnson SB, Holman RT 1996 Essential fatty acid deficiency and predisposition to lung disease in cystic fibrosis. Acta Paediatr 85:1426-1432 
6. Cristophe A, Robberecht E 1996 Current knowledge on fatty acids in cystic fibrosis. Prostaglandins Leukot Essent Fatty Acids 55:129-138

7. Roulet M, Frascarolo P, Rappaz I, Pilet M 1997 Essential fatty acid deficiency in well nourished young cystic fibrosis patients. Eur J Pediatr 156:952-956

8. Strandvik B, Gronowitz E, Enlund F, Martinsson T, Wahlström J 2001 Essential fatty acid deficiency in relation to genotype in patients with cystic fibrosis. J Pediatr 139:650-655

9. Colombo C, Bennato V, Costantini D, Valmarana L, Daccò V, Zazzeron L, Ghisleni D, Bruzzese MG, Scaglioni S, Riva E, Agostoni C 2006 Dietary and circulating polyunsaturated fatty acids in cystic fibrosis: are they related to clinical outcomes? J Pediatr Gastroenterol Nutr 43:660-664

10. Dombrowsky H, Clark GT, Rau GA, Bernhard W, Postle AD 2003 Molecular species compositions of lung and pancreas phospholipids in the CFTRtm1HGU/ tm1HGU cystic fibrosis mouse. Pediatr Res 53:447-454

11. Werner A, Bongers ME, Bijvelds MJ, de Jonghe HR, Verkade HJ 2004 No indications for altered essential fatty acid metabolism in two murine models for cystic fibrosis. J Lipid Res 45:2277-2286

12. Van Biervliet S, Vanbillemont G, Van Biervliet JP, Declercq D, Robberecht E, Christophe A 2007 Relation between fatty acid composition and clinical status or genotype in cystic fibrosis patients. Ann Nutr Metab 51:541-549

13. Coste TC, Deumer G, Reychler G, Lebecque P, Wallemacq P, Leal T 2008 Influence of pancreatic status and sex on polyunsaturated fatty acid profiles in cystic fibrosis. Clin Chem 54:388-395

14. Rosenstein BJ, Cutting GR 1998 The diagnosis of cystic fibrosis: a consensus statement. Cystic Fibrosis Foundation Consensus Panel. J Pediatr 132:589-595

15. Kalnins D, Durie PR, Pencharz P 2007 Nutritional management of cystic fibrosis patients. Curr Opin Clin Nutr Metab Care 10:348-354

16. Hernández M, Castellet J, Narvaiza JL, Rincón JM, Ruiz I, Sánchez E, Sobradillo B, Zurimendi A 1988 Curvas y tablas de crecimiento. Instituto sobre crecimiento y desarrollo. Ed Garsi, Madrid, pp 1463-1465

17. Mayer OH, Jawad AF, McDonough J, Allen J 2008 Lung function in 3-5-year-old children with cystic fibrosis. Pediatr Pulmonol 43:1214-1223

18. Walkowiak J, Nousia-Arvanitakis S, Cade A, Kashirskaya N, Piotrowski R, Strzykala K, Kouniou M, Pogorzelski A, Sands D, Kapranov N 2002 Fecal elastase-1 cut-off levels in the assessment of exocrine pancreatic function in cystic fibrosis. J Cyst Fibros 1:260-264

19. Williams SG, Evanson JE, Barrett N, Hodson ME, Boultbee JE, Westaby D 1995 An ultrasound scoring system for the diagnosis of liver disease in cystic fibrosis. J Hepatol 22:513-521

20. Lepage G, Roy CC 1986 Direct transesterification of all classes of lipids in one step reaction. J Lipid Res 27:114-120

21. Batal I, Ericsoussi MB, Cluette-Broen JE, O’Sullivan BP, Freedman SD, Savaille JE, Laposata M 2007 Potential utility of plasma fatty acids analysis in the diagnosis of cystic fibrosis. Clin Chem 53:78-84

22. Holman RT 1960 The ratio of trienoic: tetraenoic acids in tissue lipids as measure of essential fatty acid requirement. J Nutr 70:405-410

23. Keen C, Olin AC, Edentoft A, Gronowitz E, Strandvik B 2007 Airway nitric oxide in patients with cystic fibrosis is associated with pancreatic function, pseudomonas infection, and polyunsaturated fatty acids. Chest 131:1857-1864

24. Van Biervliet S, Devos M, Delhaye T, Van Biervliet JP, Robberecht E, Christophe A 2008 Oral DHA supplementation in $\Delta$ F508 homozygous cystic fibrosis patients. Prostaglandins Leukot Essent Fatty Acids 78:109-115

25. Cawood AL, Carroll MP, Wootton SA, Calder PC 2005 Is there a case for n-3 fatty acid supplementation in cystic fibrosis? Curr Opin Clin Nutr Metab Care 8:153-159
26. Asayama K, Sandhir R, Sheikh FG, Hayashibe H, Nakane T, Singh I 1999 Increased peroxisomal fatty acid beta-oxidation and enhanced expression of peroxisome proliferator-activated receptor-alpha in diabetic rat liver. Mol Cell Biochem 194:227-234

27. Bradbury NA, Jilling T, Berta G, Sorscher EJ, Bridges RJ, Kirk KL 1992 Regulation of plasma membrane recycling by CFTR. Science 256:530-532

28. Al-Turkmani MR, Andersson C, Alturkmani R, Katrangi W, Cluette-Brown JE, Freedman SD, Laposata M 2008 A mechanism accounting for the low cellular level of linoleic acid in cystic fibrosis and its reversal by DHA. J Lipid Res 49:1946-1954

29. Kang JX, Man SF, Brown NE, Labrecque PA, Clandinin MT 1992 The chloride channel blocker anthracene 9-carboxylate inhibits fatty acid incorporation into phospholipid in cultured human airway epithelial cells. Biochem J 285:725-729

30. Andersson C, Al-Turkmani MR, Savaille JE, Alturkmani R, Katrangi W, CluetteBrown JE, Zaman MM, Laposata M, Freedman SD 2008 Cell culture models demonstrate that CFTR dysfunction leads to defective fatty acid composition and metabolism. J Lipid Res 49:1692-1700

31. Zamaria N 2004 Alteration of polyunsaturated fatty acids status and metabolism in health and disease. Reprod Nutr Dev 44:273-282

32. van Dorp D, Beerthuis RK, Nugteren DH, Vonkeman H 1964 The biosynthesis of prostaglandins. Biochim Biophys Acta 90:204-207

33. Freedman SD, Katz MH, Parker EM, Laposata M, Urman MY, Alvarez JG 1999 A membrane lipid imbalance plays a role in the phenotypic expression of cystic fibrosis in cftr $(-/-)$ mice. Proc Natl Acad Sci USA 96:13995-14000

34. Strandvik B, Svensson E, Seyberth HW 1996 Prostanoid biosynthesis in patients with cystic fibrosis. Prostaglandins Leukot Essent Fatty Acids 55:419-425

35. Lauritzen L, Hansen HS, Jorgensen MH, Michaelsen KF 2001 The essentiality of long chain n-3 fatty acid in relation to development and function of the brain and retina. Prog Lipid Res 40:1-94

36. Dijck-Brouwer DA, Hadders-Algra M, Bouwstra H, Decsi T, Boehm G, Martini IA Boersma ER, Muskiet FA 2005 Lower fetal status of docosahexaenoic acid, arachidonic acid and essential fatty acids is associated with less favourable neonatal neurological condition. Prostaglandins Leukot Essent Fatty Acids 72:21-28

37. Hong S, Gronert K, Devchand PR, Moussignac RL, Serhan CN 2003 Novel docosatrienes and 17S-resolvins generated from dosahexanoic acid in murine brain, human blood and glial cells: autocoids in anti-inflammation. J Biol Chem 278:14677-14687

38. Mukherjee PK, Marchesselli VL, Serhan CN, Bazan NG 2004 Neuroprotein D1: docohexaenoic acid-derived docosatriene protects human retinal pigment epithelial cells from oxidative stress. Proc Natl Acad Sci USA 101:8491-8496

39. Borowitz D, Baker RD, Stallings V 2002 Consensus report on nutrition for pediatric patients with cystic fibrosis. J Pediatr Gastroenterol Nutr 35:246-259

40. Sinaasappel M, Stern M, Littlewood J, Wolfe S, Steinkamp G, Heijerman HG Robberecht E, Döring G 2002 Nutrition in patients with cystic fibrosis: a European consensus. J Cyst Fibros 1:51-75

41. Henderson WR, Astley SJ, McCready MM, Kushmerick P, Casey S, Becker JW, Ramsey BW 1994 Oral absorption of omega 3 fatty acids in patients with cystic fibrosis who have pancreatic insufficiency and in healthy control subjects. J Pediatr 124:400-408

42. Pacetti D, Malavolta M, Bocci F, Boselli E, Frega NG 2004 High-performance liquid chromatography/electrospray ionization ion-trap tandem mass spectrometric analysis and quantification of phosphatidylcholine molecular species in the serum of cystic fibrosis subjects supplemented with docosahexaenoic acid. Rapid Commun Mass Spectrom 18:2395-2400

43. McKarney C, Everard ML, N'Diaye T 2007 Omega-3 fatty acids (from fish oils) for cystic fibrosis. Cochrane Database Syst Rev 4:CD002201 